Ambiances

anbiances Environnement sensible, architecture et espace urbain

$2 \mid 2016$

Ambiance et histoire de l'architecture : l'expérience et l'imaginaire sensibles de l'environnement construit

\title{
From History to Architectural Imagination: A physical ambiences laboratory to interpret past sensory experiences and speculate on future spaces
}

De l'histoire à l'imagination architecturale. Un laboratoire d'ambiances

physiques pour interpréter les expériences sensorielles du passé et spéculer sur

de futurs espaces

Claude MH Demers and André Potvin

\section{OpenEdition}

\section{Journals}

Electronic version

URL: http://journals.openedition.org/ambiances/756

DOI: $10.4000 / a m b i a n c e s .756$

ISSN: 2266-839X

Publisher:

Direction Générale des Patrimoines - DAPA - MCC, UMR 1563 - Ambiances Architectures Urbanités $(\mathrm{AAU})$

Electronic reference

Claude MH Demers and André Potvin, « From History to Architectural Imagination: A physical ambiences laboratory to interpret past sensory experiences and speculate on future spaces », Ambiances [Online], 2 | 2016, Online since 07 November 2016, connection on 10 December 2020. URL : http://journals.openedition.org/ambiances/756 ; DOI : https://doi.org/10.4000/ambiances.756

This text was automatically generated on 10 December 2020.

\section{$\Theta \Theta \Theta \Theta$}

Ambiances is licensed under a Creative Commons Attribution-NonCommercial-NoDerivatives 4.0 International License. 


\title{
From History to Architectural Imagination: A physical ambiences laboratory to interpret past sensory experiences and speculate on future spaces
}

\author{
De l'histoire à l'imagination architecturale. Un laboratoire d'ambiances \\ physiques pour interpréter les expériences sensorielles du passé et spéculer sur \\ de futurs espaces
}

Claude MH Demers and André Potvin

This paper is based on "Adaptive Architecture: Experiencing Visual and Thermal Delight in Adaptable Environments", a research-creation project that has received financial support from the Social Sciences and Humanities Research Council of Canada (SSHRC). Researchers particularly thank the M.Sc. graduate students involved in all stages of the project at the Groupe de recherche en ambiances physiques (GRAP): Alper Caglar, Cédric du Montier, Chantal Galibois and Hélène Giguère-Duval.

\section{Ambiences and the typological approach}

1 An ambience is in many ways defined by the very presence of inhabitants of a given space, but also by the very nature of the space itself. It is therefore complex, and remains a challenge to assess in its multiple human and built variables. The importance of understanding ambiences to support design research and hence develop innovative architectural solutions adapted to new contexts, coincides with our contemporary recognition that people are central to the comfort/energy performance equation of buildings. This research-creation project recognizes that the people-environment issue 
constitutes an essential basis to the creation of genuine genius loci. It proposes a physical ambiences laboratory to explore the discrepancies between the prediction and in situ experience of ambiences through evocations of spatial typologies. The contribution to architectural imagination appears in the illustration of the potential of the research to interpret, represent and speculate on existing and future ambiences.

Illustration 1: Physical ambiences laboratory built in Québec, Canada. South-facing façade

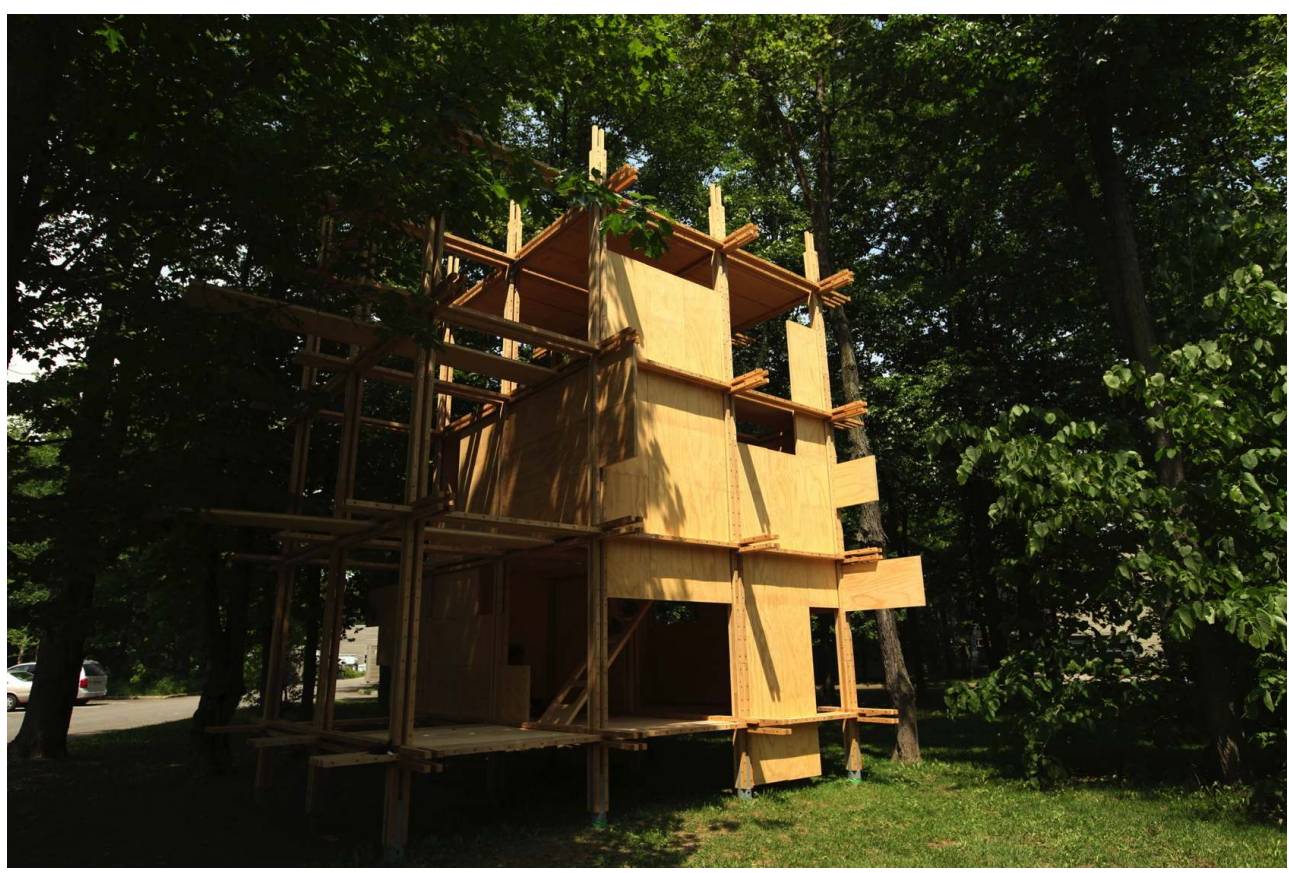

Source and copyright: Claude Demers, Groupe de recherche en Ambiances physiques, Université Laval, Canada

2 Architects have an understanding of ambiences that originates from their own experience of space, an empirical knowledge based on intuition. Intuition and sensibility toward the physical environment must also rely on a knowledge of past solutions applied to related design problems (Maldonado, 1966). The typological approach therefore constitutes a framework that conditions the act of creating (Huet, 1993). The argument often disputed against the use of typologies in the design process is that they are "a vestige of the age of craft" (Colquhoun, 1981). It states that the use of models by craftsmen became less necessary as technology developed during the pre-industrial age enabled designers to discover the physical laws of nature. Facing new constructive possibilities, the typological approach becomes a tool that could initiate a concept based on the experience of ambiences. The typology constitutes a necessary beginning, but not an objective or a result since architecture consists in going beyond it (Huet, 1993). In fact, "it plays a creative role by allowing the designer to begin the cycle of analysis and revision from a reasonably confident position" (Hawkes, 1996). The diverse environmental aspects present in an ambience ensure that morphological relationships are rarely dependant on physical laws alone (Colquhoun, 1981). Other laws relating to qualitative aspects should also contribute to the definition of typologies in architecture.

3 The built environment offers an impressive corpus of spatial typologies on which architects and users may build their knowledge based of ambiences. This corpus primarily consists of existing buildings originating from a wide spectre of historical 
backgrounds, but it could also include past ambiences that have previously existed to rediscover new potentialities of certain configurations that no longer exist. Exploring past and existing typologies of ambiences to redefine and explore future spatial configurations becomes an essential part of design thinking (Demers 1997). This is especially relevant since we are witnessing the renewal of interest for robust and simple bioclimatic design strategies that have existed in the past, in association with the resulting ambiences. It is often argued that nowadays, architectural creation is linked with the necessity to reinvent forms, morphologies and hence, lights, to make the most of new technological knowledge. The need to explore and rediscover past ambiences as architectural form in a more systematic manner to reinterpret them is eminent since most recent researches concentrate on the technical aspects of comfort and productivity. This implies the promotion of an integration of the intuitive and empirical knowledge of Masters of Architecture to the present context, of past spatial typologies to the present design activity. Throughout history, technology has considerably modified our relation to light, and by extension to other modalities of ambiences, often inhibiting and diverting the role it plays as generating forms in the new complexity of building (Zevi, 1991). It has also enabled architects to explore new typologies of spaces as building science has allowed new assembling techniques and structures. Constructive techniques have expanded the limits of transparency, and opacity is therefore no longer essential for structural support. The liberation of the space and façade offers the possibility of a new dynamic which is also responsible for the associated complexity involved in the design with light as there are fewer constructive limits. This technological era allows the possibility to extend the range of design solutions that were available in the past and to rediscover the role that physical ambiences may play as a constructive matter of space. Additionally, the discussion of ambiences integrates the relation between energy and people, which has recently become a focus of attention, allowing user's performance to be assessed. Human perception of an ambience, which corresponds to the physical character of an existing space and its emotive response, is multisensory. The relation between objects themselves such as windows and structures, or between objects and users create perceptual interpretations of new and dynamic spaces (Arnheim, 1978). In terms of evaluation, an ambience may be assessed through a number of sensations including the thermal, luminous, olfactory and acoustical, which are essential parts of today's architectural challenges to support the design for sustainable buildings of the future. The knowledge and prediction associated with these aspects, referred to physical ambiences, also includes the qualitative and quantitative measurements. Challenges of our sensory response to the built environment are therefore central to propose solutions that are not only satisfying to inhabitants of a space, but are relevant to attain a certain level of delight and a sense of empowerment, therefore surpassing actual prescribed norms of comfort. Additionally, the knowledge associated with quantitatively evaluating physical ambiences is associated to sustainable goals for architecture and engineering.

The discussion, measure and evaluation of ambiences in architecture may occur in several ways, but perhaps the most important aspect aims to converge theoretical and applied knowledge, which may happen through actual experimentation of a space or in situ evaluation. Existing spaces offer the advantage to experience actual ambiences in real time, enabling to assess quantitative parameters as well as qualitative ones, enabling architects and users to be able to speculate and eventually create new habitats. The in situ experience of built forms constitutes an invaluable source of information that 
enriches the potential for architects to develop their empirical knowledge and share creative ideas with clients.

Past ambiences of iconic buildings are often lost with the disappearance of their physical support, considerably limiting the possibilities of their assessment. In those cases, drawings and photographs provide a relatively effective support to extract clues that partly recover components of an ambience. Architectural imagination may indeed be triggered through the manipulation and transformation of drawings and photographs. Figure 2 illustrates the use of photographs of past ambiences to convince designers and clients to develop a skylight building typology for the design of a new woodworking laboratory, the Eugene H. Kruger Building at Laval University. The Groupe de recherche en ambiances physiques (GRAP) had the mandate to guide the client and architectural design team in predicting ambiences and comfort for the new building. Photographs of long gone factories of the early 20th century provided additional evidence to reintegrate the skylight typology in the new design. Although skylights were regular features of the late 19th century factory buildings in Quebec City, snow accumulations and associated constructive liabilities compromised their practical application. Deeper plan buildings without dominant daylighting strategies have been the norm since the 1960's. The old black and white photographs showed workers operating machines in relation to a daylighting task, reminding clients and designers that architecture is, after all, made for people to feel comfortable, but also connected to the exterior, and therefore, happier and perhaps more productive. Photography provided arguments favouring the rediscovery of a past typology to interpret and adapt it to a different but similar human activity for the proposed building. Design proposals for the new woodworking lab included a reappropriation of skylights in a more energy efficient design (figure 2, right). In that case, reinterpretation of a past ambience became an initial basis on which to think about a new design solution for today's applications. Physical scale models were built to establish the relation between space and light, but at the time, very limited knowledge was available in terms of the multisensory experience that included the thermal and visual aspects. Even after a series of analogical and numerical simulations, the design team remained unsure of several issues related to the integration of such feature in association with a task that was highly demanding in terms of visual acuity and thermal comfort. The occupation of the building (figure 2, right) provided the first insight, which surpassed all quantitative and qualitative expectations in terms of environmental delight (Knowles, 1999). Incidentally, the elaboration of a full-scale physical ambiences laboratory, which is the core of this paper, occurred in that very workshop. Although drawings and photographs can act as witnesses of the past and foster imagination, the full-scale experimentation of a space remains the only mean to assess habitability and the inhabitants-architecture transactions. 
Illustration 2: Past and future spaces: differences and similarities

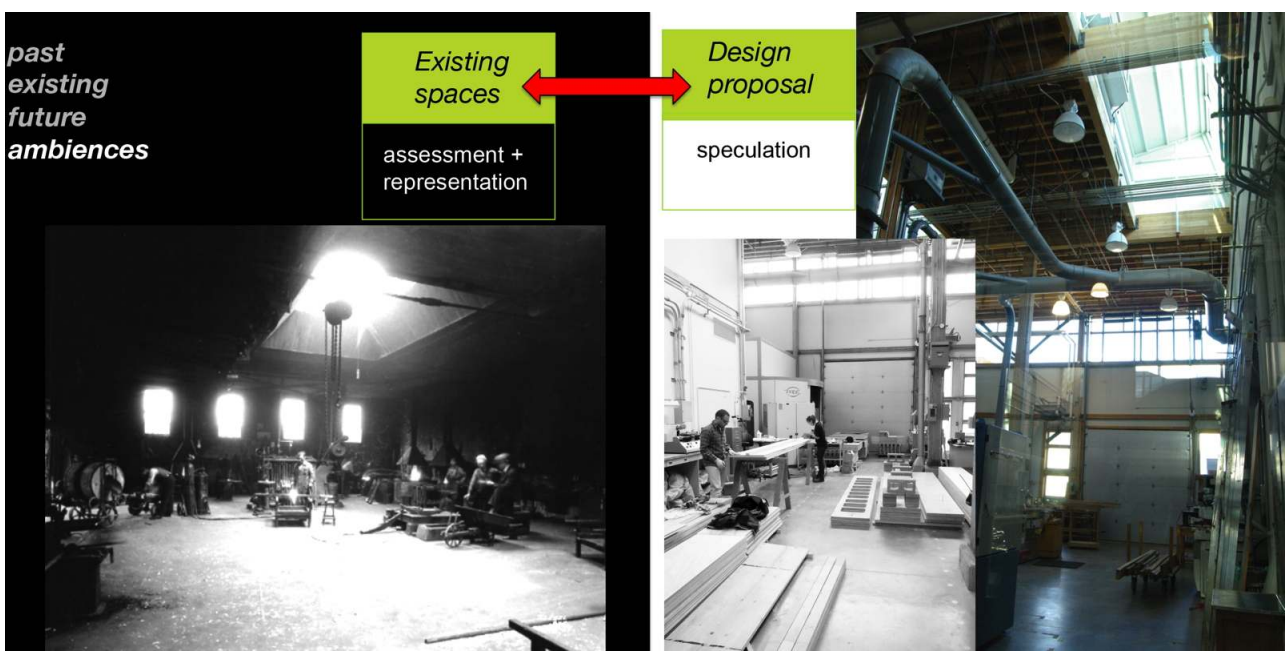

Skylighting typology in a historical architectural precedent in Québec (left). Inhabiting a laboratory (right), which design was triggered by the study of old photographs.

Source and copyright: Ville de Québec, archives. Document du domaine public, libre de droits (Left image). Chantal Galibois (center image) and Claude Demers (right) Groupe de recherche en Ambiances physiques, Université Laval, Canada

Closely linked with the act of creation and more effectively than any other types of representation, the full scale physical ambiences laboratory acknowledges that in situ experimentation of existing buildings remains an ideal mean to take advantage of the complexity of all physical and perceptual aspects related to ambiences. The physical ambiences laboratory should provide a privileged framework to interpret and experiment iconic historical typologies of spaces at the scale of an observer. It does not substitute the experience of any existing space, but rather allows a critical and versatile way of addressing new ambiences. Architectural imagination could therefore be triggered more realistically because of its tactile connection and its human scale, close to ergonomic considerations. This should allow architects, designers and users to speculate on future ambiences with more confidence.

\section{Imagining a physical ambiences laboratory}

7 A physical ambiences laboratory has recently been developed, built, and inhabited to compare existing and past ambiences, but foremostly speculate on future ambiences. It consists of a full-scale, adaptable structure that allows for the experience of a relatively large array of architectural typologies, and enables spatial transformations through time (Demers et.al. 2013). The concept of the ambiences laboratory is reminiscent of Kiesler's idea of a flexible habitat that is "as elastic as the vital functions" (1947), a space which could be transformed in relation to its environment. Its structural composition is also a reminder of City in Space, also designed by Kiesler in 1925, a monumental structure that explores horizontal and vertical panel compositions that expand the notion of free space and the liberation from the ground. Within the ambiences laboratory, past and innovative architectural typologies become vivid spaces due to the highly adaptive structural system specifically designed for that purpose. The physical ambiences laboratory allows almost simultaneous comparison of several building typologies, past and present, and transform 
them into new projections of ambiences. Interpretation of existing and past ambiences therefore raises many questions, particularly for spaces that no longer exist, and especially for qualitative parameters, which relate to the complexity of the relation human-environment. In situ experimentations also relate to the complex nature of the physical context of a particular site, which transcends the visual dimension to include the thermal, acoustical and olfactory dimensions. The natural conditions of a place, which includes the continuous changes of daily and seasonal rhythms are contrasting with the relative stability of the physical form to create a genius loci (Norberg-Schulz, 1980). In that view, the ambience laboratory acknowledges the systemic nature of comfort and becomes a unique tool to explore the entire potential of physical ambiences in relation to an actual environmental context. It therefore informs designers of new opportunities to generate imaginative solutions for tomorrow's buildings.

Building the adaptable structure in an outdoors environment aims to connect the theory of ambiences with the actual complexity of experiencing on a site, which cannot be adequately approached with digital simulation. The definition of an ambience therefore involves complexity because of the changing nature of the environmental conditions that generates it, such as light, wind, sun, and sound, creating varying distribution patterns of natural fluxes. The physical ambiences laboratory much compares with physical models that architects build for communication and validation purposes, but with the added possibility to leisurely inhabit the space and experience its complex sensory connection with the exterior, at different times of the day, and for a particular site since it can be dismantled and re-installed in another location under an entirely different structural configuration. By definition, a laboratory enables comparison of objects in a relatively controlled environment, which allows the comparison of a selection of variables with predominant importance in relation to design objectives. Transparency and opacity, the main components central to the basic definition of an archetype in terms of physical ambiences, were chosen as main variables attributed to architectural typologies. Materiality of the full-scale structure included flexibility and robustness of the model since the most important aspect consists in the interpretation in simple terms of its main ambient components that define the interior-exterior relation. The laboratory therefore acts as a filter to propose a new and open interpretation of an ambience, rather than to replicate the existing space. Even when replicating some features of a past ambience or space, known variables would almost always make the actual experience similar to the existent building, but not entirely identical. The ambience laboratory aims to discuss the possibility to compare building typologies within the same restraints by limiting effects linked with particular colours, finishes, details. Indeed, an ambience may very well depend on those details to produce an effect. In the act of creation, models need to abstract parts of the reality of an existing space to offer more freedom of interpretation. As an example, architects use abstraction to concentrate on the location of opacity and transparency to interpret a spatial relation existing between human perception and environmental factors.

The specially developed structure has been built of repetitive wooden elements that can be moved in three directions to vary the opacity of the system to create modular transformations of the laboratory (figures 1 and 3). The structure had to be limited in its dimensions, size, number of nodes and planes (figure 4). The design of the adaptable system aimed to generate the maximal number of positions within the minimal number of wood members. Other types of structures could be looked into, but the adaptable 
potential of the system was considered as an essential criterion to produce the widest range of conditions. It was also the very first version of such a large-scale inhabitable and modular system to study ambiences, a relatively ambitious project that had to be tackled before developing more complex and larger modules. The more controllable solution, reduced in constructive material and size, would at least in a certain way, enable the exploration of a series of typologies in a relatively short time and in a unique context. The simplicity of the orthogonal structure and its movable elements opens up the possibilities of complex architectural forms (Potvin 2014). It provides the opportunity for the real scale environmental experimentation of existing iconic buildings and past spaces in a simplified way. It was developed through funded design research project entitled Adaptive Architecture: Experiencing Visual and Thermal Delight in Adaptable Environments (Demers, Potvin, SSHRC 2009-2013), enabling to build a 1: $3 / 4$ scale structure measuring 6.6 m long x 4.2 m large x 6.6 m high. Long and narrow $4.2 \mathrm{~m}$ x $0,6 \mathrm{~m}$ light wooden panels offer a large spectre of spatial explorations through translation between the rigid structural nodes and bridge members. "Inhabitants" can therefore modify the location of apertures within wall, roofs and floors to redefine the horizontal and vertical relationships between interior and exterior.

10 The opacity and transparency dialogue occurs within the simple process of sliding and adjusting a series of vertical and horizontal wood panels, strategically located within the structure to produce a synthesis of the space. The explored configurations, such as shown in figure 3, are illustrations of generic solutions that could be applied in a diverse array of contexts at particular moments and, as previously mentioned, do not attempt to replicate an original space nor constitute an end in terms of experiences. Initial physical model studies were used to establish the potential of the structure in terms of exploring a diverse and wide range of typologies solutions that could be explored. The most "opaque" and thus interiorised environment consists of a cubic space totally enclosed (figure 3a, top left image), which corresponds to the initial stage of the laboratory. For practical and safety reasons, and because the laboratory is built in an exterior environment accessible by the public, this stage represents the structure in a totally closed configuration, making sure that uninvited users will not occupy the lab between experimentations. Theoretically, this totally enclosed space represents the most exclusive spatial configuration. Such enclosed spaces, typical of post-industrial architecture wherein mechanization took command of the interior-exterior environnemental transactions, are still common in today's practice. Deep plan buildings represent the paradigm of environmental exclusivity, lacking in visual, acoustical and thermal information about the outdoor conditions. On the contrary, selective typologies offer a diverse range of indoor-outdoor relationships that can creatively be extrapolated in many combinations of pulling and sliding panels. For instance, a solution may result in a totally open space to the sky, such as shown in figure $3 \mathrm{~b}$, which would correspond to a top lit typology connected with a series of exterior terraces. Although physical scale models allowed the insertion of materials of various transparency and colour, the full-scale laboratory is limited to opaque panels. It should be noted that the construction of the laboratory, as well as all transformations are made using the minimal physical and mechanical effort (Potvin 2014). 
Illustration 3: From opacity to transparency
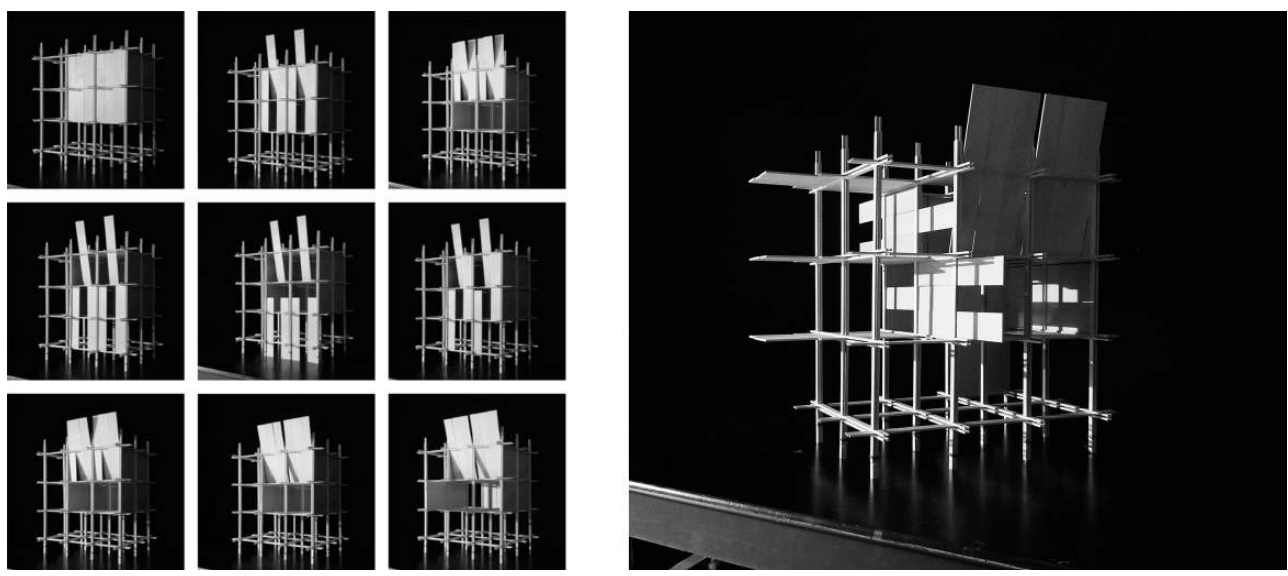

Initial physical model studies to establish the potential of the structure to explore a wide range of typologies. Series of data, from the cubic configuration (left) to the expanded version (right).

Source and copyright: Claude Demers, Groupe de recherche en Ambiances physiques, Université Laval, Canada

Illustration 4: Construction of the laboratory
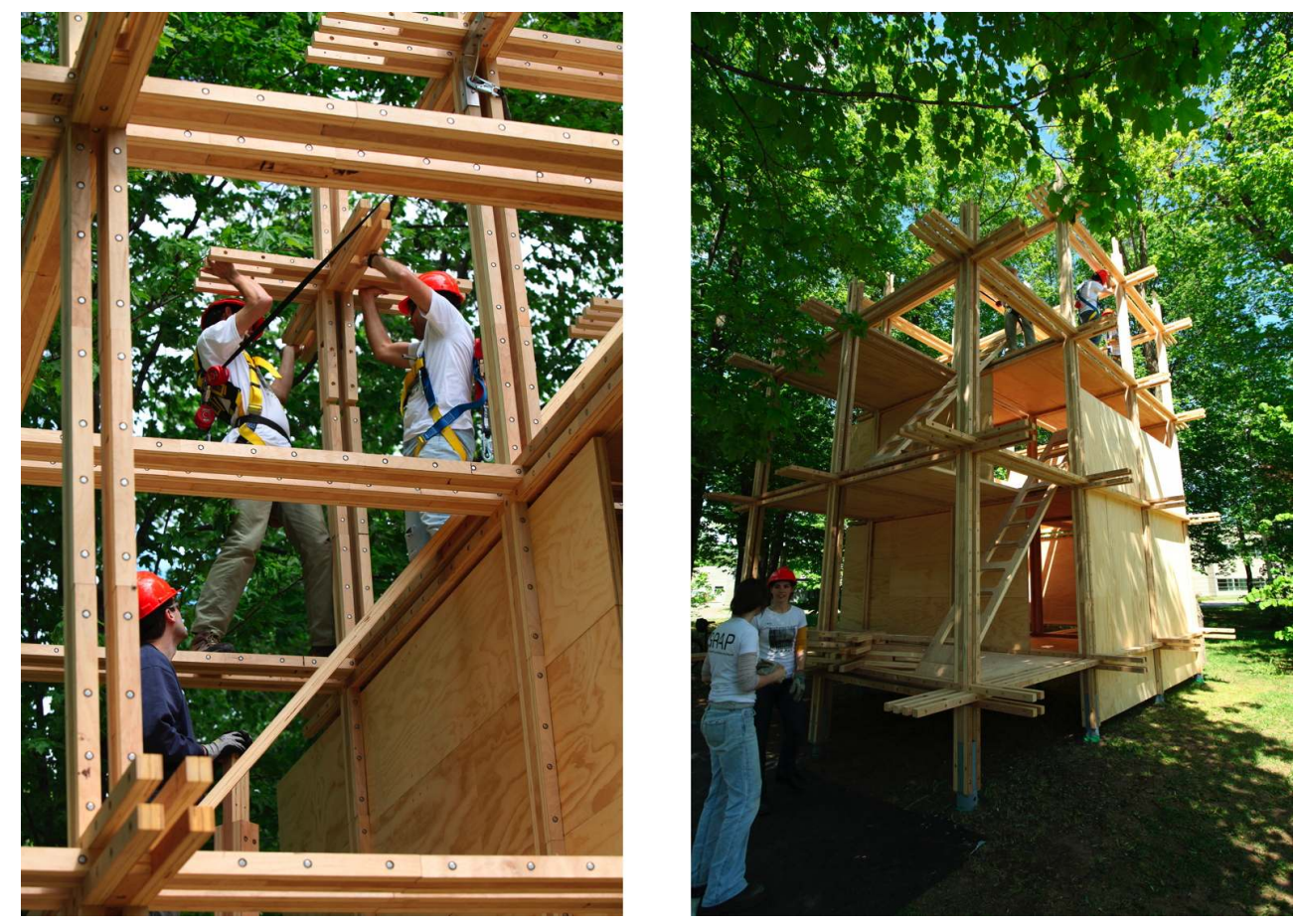

The laboratory consists of custom wooden rigid nodes that allows movements of lightweight laminated veneer panels in all directions.

Source and copyright: Claude Demers, Groupe de recherche en Ambiances physiques, Université Laval, Canada

11 The relevance of building the physical ambiences laboratory on an actual site and at full scale was immediately confirmed on the very day of its completion. After erecting the structure (figure 4 (right), students that had been working on the construction site were excited, instinctually interacting with the structure, creating a spontaneous choreography of body adaptations with architecture (figures $5 \& 6$ ). They had previously 
known the space through design thinking and construction. Now, animated by an architectural invitation to rediscover spatiality through play, an unplanned experience could be achieved because of the new possibilities offered by a full-scale structure acting as an ambience laboratory. The possibility to liberally enjoy the space, inhabit and "feel" the structure, touch its limits and measure it with bodies created an energetic exchange between "inhabitants". The experience emphasized the exploration of the ergonomic potential of the adaptable structure, and certainly offered an opportunity to daydream about its many futures (figure 6). There were students lying on the edge of structural elements, wrapping around columns, hanging through walls, or even stretching across spaces. In their terms, these inhabitants were experiencing pure happiness, delight and even a certain pleasure, thinking about the next move to try, playfully. They were using the structure in ways that had not been planned in any of our occupational scenarios. This is not uncommon in architecture, and we assume that a certain delight could be attained when a space invites spontaneous activities to occur in response to inhabitants' biological needs. Baker (1995) studied the adaptive nature of inhabitants in seeking comfort. He introduced the term 'adaptive opportunities' to describe the provision of adaptable features provided by buildings to their inhabitants. The physical ambiences laboratory therefore maximises these adaptive opportunities and generates innovative ways to inhabit space. This happening or experience also relates to Kahn's notion of the realm of architecture (Kahn, 1959), which is genuinely human and experiential. Kahn's definition emphasizes that the essence of architecture relates to a complex set of elements that converge to touch its limits. In fact, it consists of a true experience of Le Corbusier's notion of "acquired knowledge" (Le Corbusier, 1923) whereas different types of theoretical or practical understandings of a subject are included. The realm of architecture obviously includes qualitative as well as quantitative aspects. We therefore acknowledge the importance of architectural delight and beauty, which are enriching our daily lives and people's well-being. The terms delight and pleasure perhaps more implicitly relate to the tactile and experiential nature of architecture. Habitability is discussed at three spatial scales corresponding to three design thinking steps at the site, architecture, and material scales. While the site is the ultimate reference for positioning a project in terms of climate and environment, the architectural scale refers to the body and the way we inhabit space, and the material scale emphasizes tactile interactions with architecture. 
Illustration 5: Body, space, context: an unplanned "performance" that occurred right after erecting the structure on its site
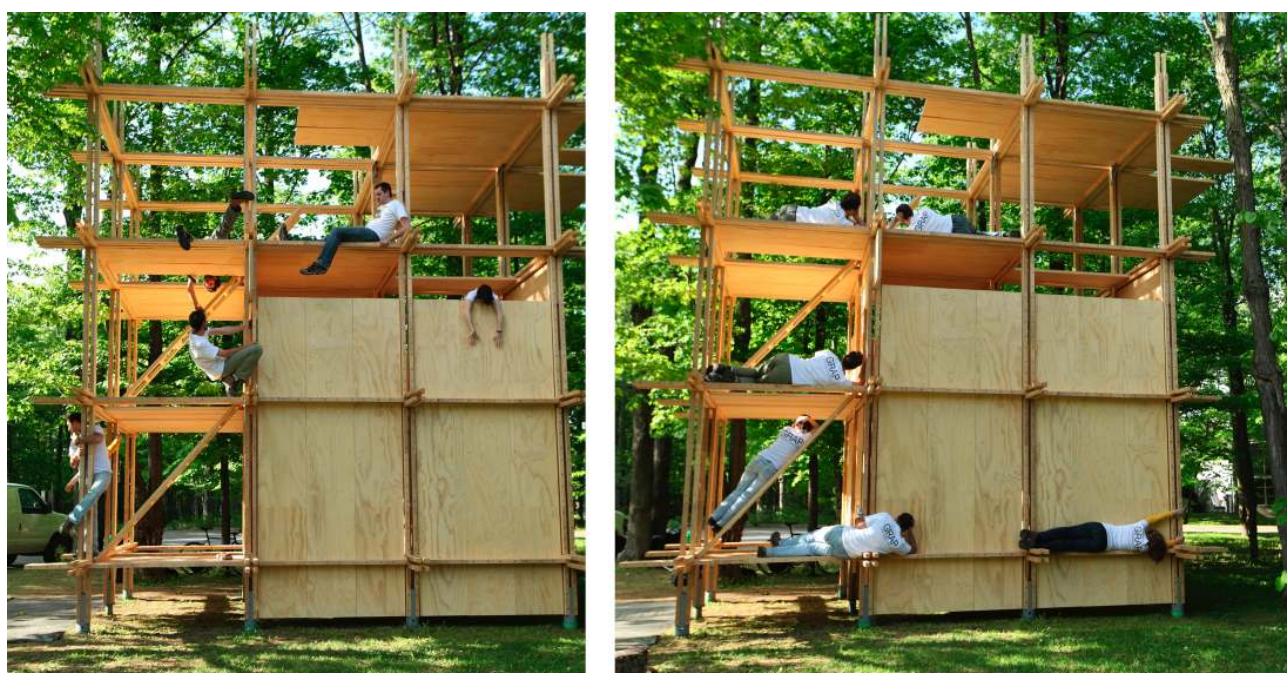

Source and copyright: Claude Demers, Groupe de recherche en Ambiances physiques, Université Laval, Canada

Illustration 6: Exploring the body and structural limits

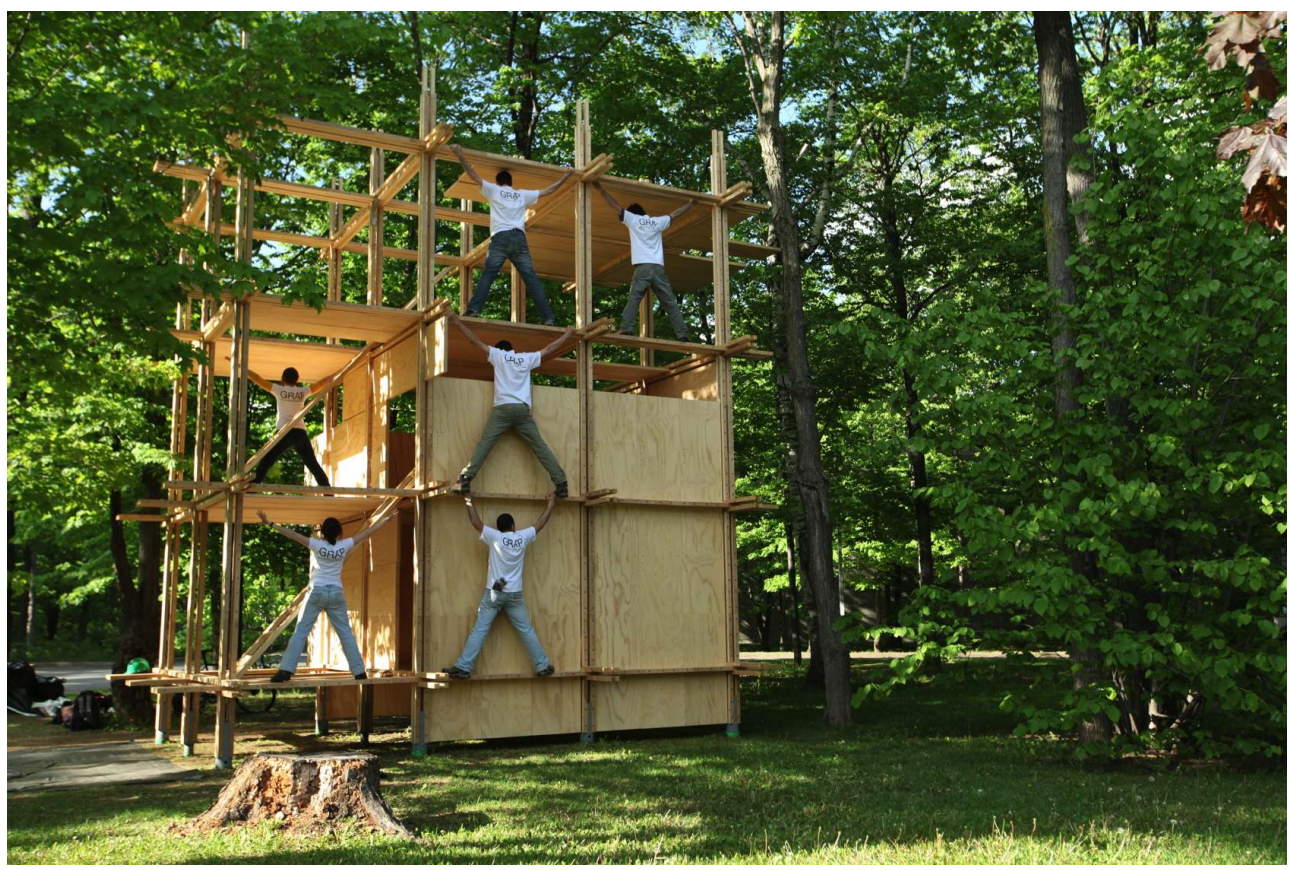

Source and copyright: Claude Demers, Groupe de recherche en Ambiances physiques, Université Laval, Canada

\section{Assessing physical ambiences in motion}

12 Theoretical knowledge accumulated through surveys is instrumental to the design of comfortable spaces that provide favorable environmental conditions to perform specific tasks, but also to respond to biophilia principles, such as a greater connection between 
the interior and exterior. This design-research approach therefore addresses qualitative (subjective) aspects of space as well as quantitative aspects involved in the technological resolutions within the context of sustainable architecture. The experience of space, generated by people's response to the environment in relation to their senses, is closely linked with inhabiting and transforming spaces according to personal needs in the physical ambiences laboratory. Ambiences were therefore analysed as physical as well as perceived phenomenon in the generated variations of spaces, from "complex to simplex" events (Woloszyn \& Siret, 1998) at the urban, architectural and material scales. Reading and evaluating an ambience enables architects to understand the qualitative and quantitative dimensions encompassing the physical and sensorial components of architecture (Lam, 1986). There exist many types of measuring tools that can assess the environment, but ultimately, the user is always central to questions related to spatial experiences, as buildings should mainly respond to people's needs. New technologies developed in relation to monitoring buildings, and in particular in relation to imaging and visual representation can provide a relatively confident assessment and representation of physical ambiences that can complement other assessment techniques based on human responses to environments. These technologies are particularly effective in the measure and representation of the visual and thermal environment at full scale (Lépine, 2011), and can even be addressed to explore scale models (figure 7). Images issued from physical model provide generally external views, limiting the interaction between user and space. A series of experiments were planned during the development of a prototype for the physical ambiences laboratory to explore its potential and limits in evaluating ambiences. Scale modeling enabled rapid changes and a usually larger amount of spatial variables, but was obviously very limiting in terms of tactile connection between user and space. The interaction of lighting, thermal and acoustical ambiences with people's sensibility is significant since it greatly affects the perception of space. It was therefore expected that the full-scale version would add the possibility for the user to interact more extensively with the space.

Illustration 7: Visualization of physical ambiences using physical modeling

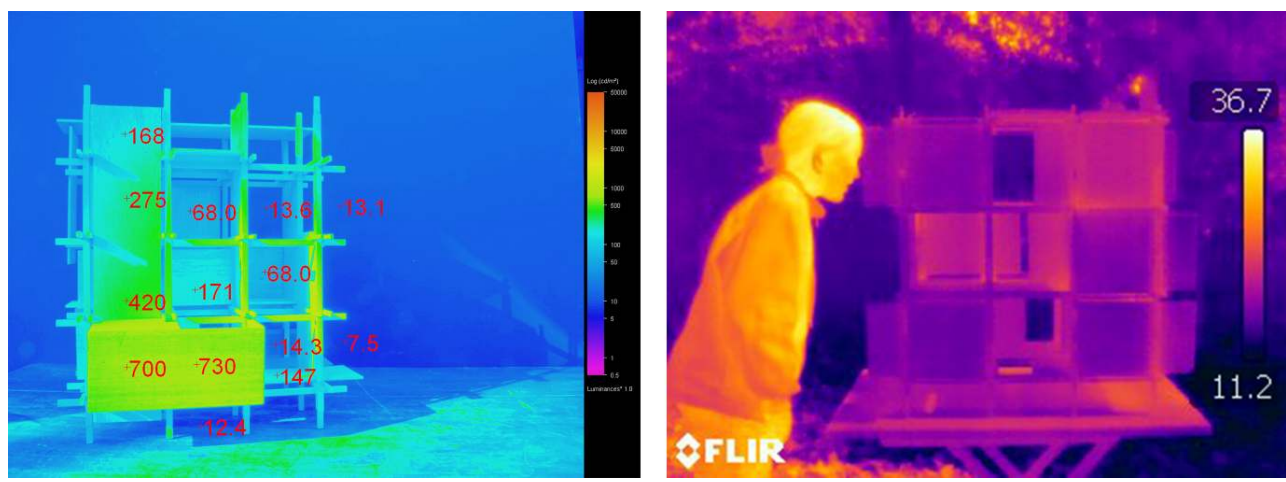

LIgHTINg PATTERN USINg THE PHOTOLUX PHOTO-LUMINANCEMETER, A CALIBRATED CAMERA SYSTEM (LEFT). THERMAL IMAgINg PHOTOgRAPH SHOWINg RELATIVE TEMPERATURES ON SURFACES USINg A FLIR CAMERA (RIgHT).

Source and copyright: Claude Demers, Groupe de recherche en Ambiances physiques, Université Laval, Canada

13 A typical experience in the physical ambiences laboratory begins when approaching the initial enclosed cubic configuration standing on the site (figure 8, upper left image) and acknowledging the environmental character of the surrounding site, which includes 
measurable parameters such as temperature, wind and sunlighting exposure. Exploring ambiences within the laboratory requires physical actions of humans sliding panels to the space (figure 9, left), but also to initiate the discussion on of the interior-exterior relation by physically manipulating and experiencing the progression of those transformations (figure 9). This process of simulating an existing or even past architectural typology involves a certain rationalisation of its dominating features in terms of opacity and transparency. The translation of the most important components that represent a space typology needs to be addressed in relation to the aims of the experience of an ambience. From an exclusive and opaque neutral space emerges the more selective spaces bridging interior and exterior through active inhabitants' interactions.

Illustration 8: A sequence of transformations occurring within the laboratory
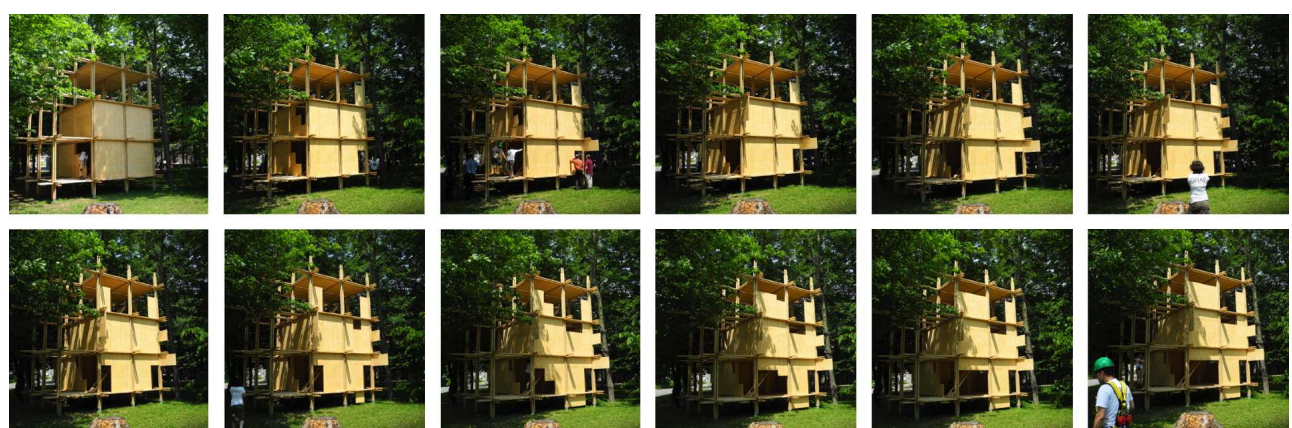

PHOTOgRAPHS FROM THE SOUTHERN “FAÇADE”.

Source and copyright: André Potvin, Groupe de recherche en Ambiances physiques, Université Laval, Canada 

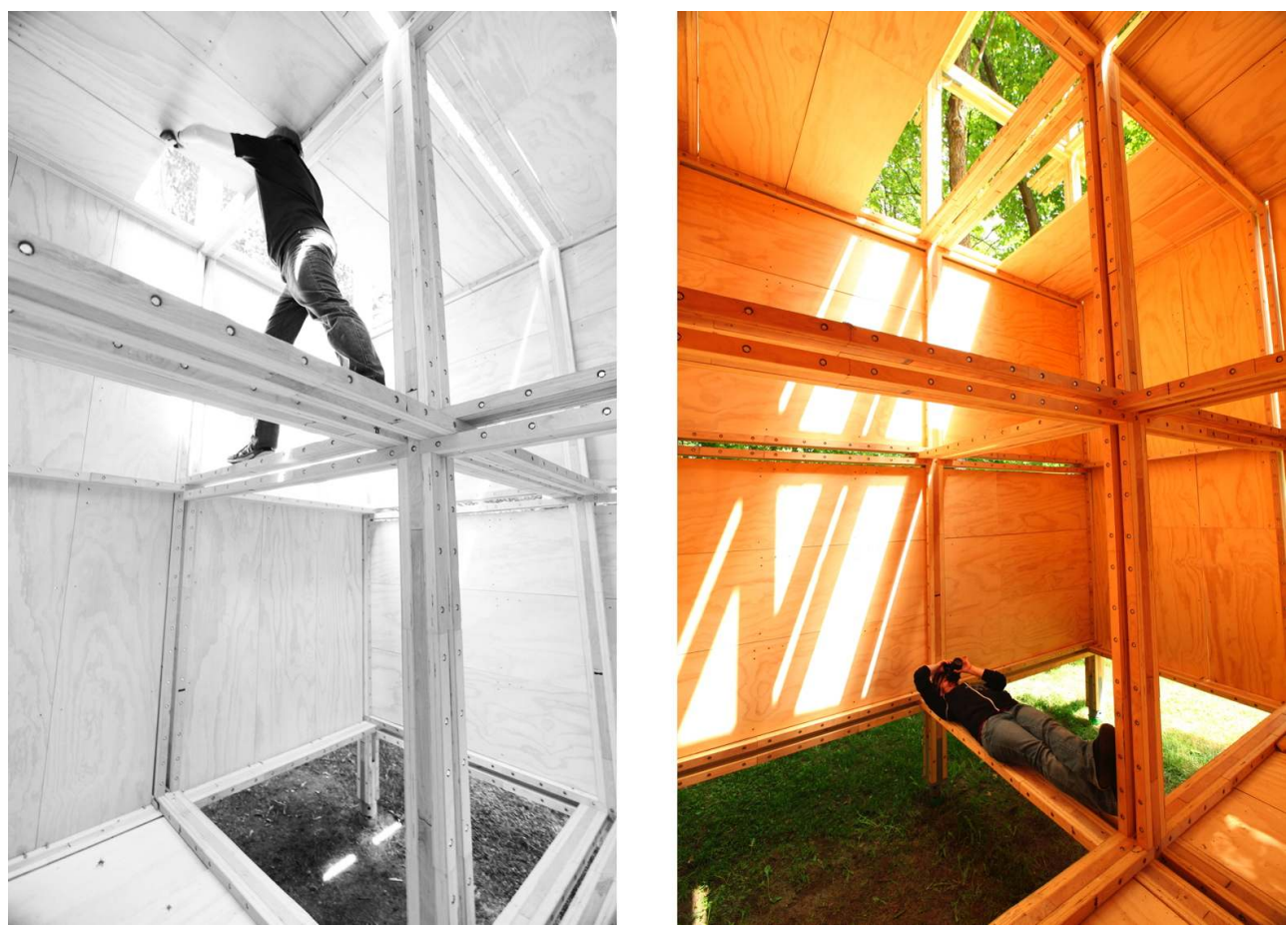

INHABITANT'S ACTIONS (LEFT) OF MOVING THE PANELS WITHIN THE STRUCTURE TO ACHIEVE A SPATIAL CONFIGURATION OF A SPACE. EXPERIMENTING WITH DIFFERENT BODY ADAPTATION AND CAPTURING AN AMBIENCE DURING THE PROCESS OF TRANSFORMATION OF THE STRUCTURE (RIgHT).

Source and copyright: Claude Demers, Groupe de recherche en Ambiances physiques, Université Laval, Canada

Uncovering the new space involves creating an initial aperture in the cubic initial configuration of panels that will act as an entry to the lab. This physical interaction happens when "researchers" use light tools and their body energy to slide the panels between the structural elements. The laboratory imposes new physical activities within the day, and invites the inhabitant's body to react to space and environment. The relative position of the body in space, a personal reference that connects people with perceptual references, is challenged in revisiting the design options that were initially planned. Figure 9 (right) shows an inhabitant that took the opportunity to lie down on one of the structural bridges of the structure between transformations of the typology and eventually proceeded to visually and thermally survey the very viewpoint that was felt as being delightful. In fact, the adaptive structure becomes a tool that interacts, within the creative design thinking process, at the full scale of space and body. Gravity is especially experienced as panels are moved upwardly, such as in the configuration shown in figure 10. Forces related to the friction of wood panels against the structure are also felt while displacing a horizontal panel. Physical forces applied by an inhabitant to the moving of a panel become part of the dynamic experience of structural adaptations. For instance, it was discovered that moving vertical panels sideways created a new door of varying sizes, whereas sliding lower ground horizontal panels provided a terrace to rest in this newly created interior-exterior space. This principle of sliding a panel inevitably constructs interplays of voids and filled spaces. It also invites us to revise our initial design predictions of spatial typology as we experience a transformation. 
The transformation of a space into another configuration often morphed into unplanned results where the intermediate steps of transformation literally created physical ambiences in motion. The simultaneous awareness of people inside and outside the model therefore enriches the uncovering of new ambiences and experiences of the body in space, which could not be achieved in smaller scale models (figure 7) or even digital simulation. At anytime of the experience or transformation of the space, the process may be stopped to actually take time to "live" within the newly created configuration. For instance, "users" might rest during a lunch break within the structure to take advantage of the warmer interior and sunny protected space (figures 10 right and 11). Figure 9 shows users at the first level of the interior space discovering the bright grassy area, which has been revealed by sliding horizontal floor panels. A newly displaced panel located above the entry offers protection and directs the view towards the interior, which has also created an open area in the ceiling of this ground floor (figure 4 right). An invitation to enter the inner space and even climb up the "stairs" from the entry located at the left west façade (figure 10 left). The created panoramic view of the open corners generates a window typology which bears similarities with Scarpa's daylighting strategies, which is perhaps not fully adapted to Nordic winters, but could well be perfect for this hot summer day. After several experiences of typologies through adaptations of the structure, resulting compositions and their variations are taking place in the actionreaction process of sliding panels in relation to needs expressed through experience. It produces a series of spaces that can be appreciated at different levels of their creation, as a work in progress rather than in its finality. The resulting configuration may have been developed from the additive manipulation of panels happening over an entire day to adapt to new environmental conditions, or it might be carefully planned to reconstruct and interpret an existing architectural typology.

Illustration 10: An indented type of façade
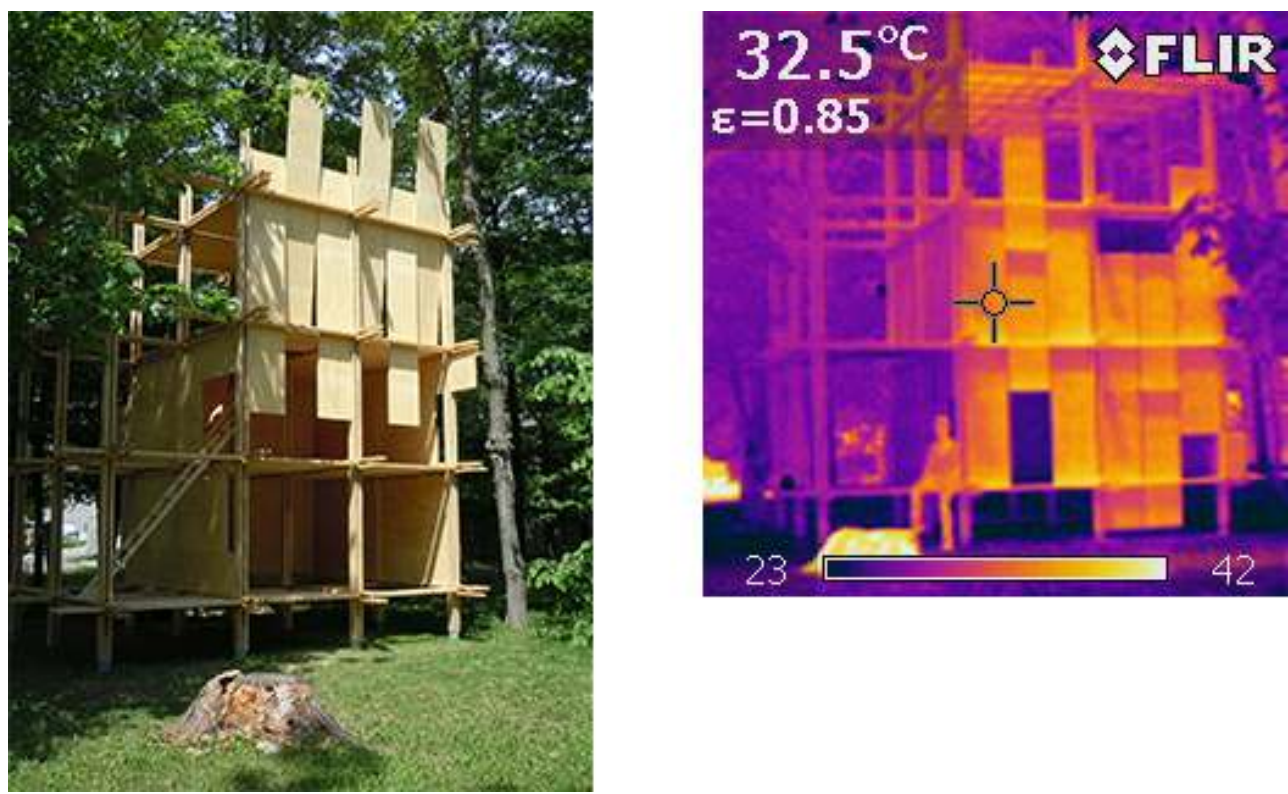

AN INDENTED TYPE OF FAÇADE, ALLOWINg AN OPEN SPACE ON THE fiRST FLOOR (LEFT). THERMOgRAPHIC IMAgE OBTAINED DURING THE PROCESS OF ACHIEVINg THE CONFIgURATION, SHOWINg THE SHADED AREA CHOSEN BY THE "PERFORMER" (RIgHT).

Source and copyright: André Potvin (left image) and Hélène Giguère-Duval (right), Groupe de recherche en Ambiances physiques, Université Laval, Canada 
The relative position of the body in space is constantly challenged by new possibilities unthought-of in the initial space configuration. The new façade created during the displacement of panels involved a series of transformations in particular on the southfacing façade (figures 10,11). The exterior semi-protected terrace welcomes an inhabitant sitting on its edge. He is leaning on one of the vertical members of the façade, his body external temperature suggests a symbiosis with the wood material, as illustrated in figure 10 (right). The direct light of the sun produces sharp shadow patterns and is generally felt as uplifting. It generates high contrast in the visual field, which needs to be controlled, highlights textures on surfaces, and even materializes on small particles in the air such as dust and humidity, creating effects of sunrays in south-facing spaces. In certain cases, the thermal sensation associated with sunlighting will contradict notions of comfort. This is shown in figure 11 (right) whereas an inhabitant is resting in on her back, clearly enjoying an uneven thermal pattern on her body.

Illustration 11: Feeling light and heat: the position of bodies in relation to apertures within a space
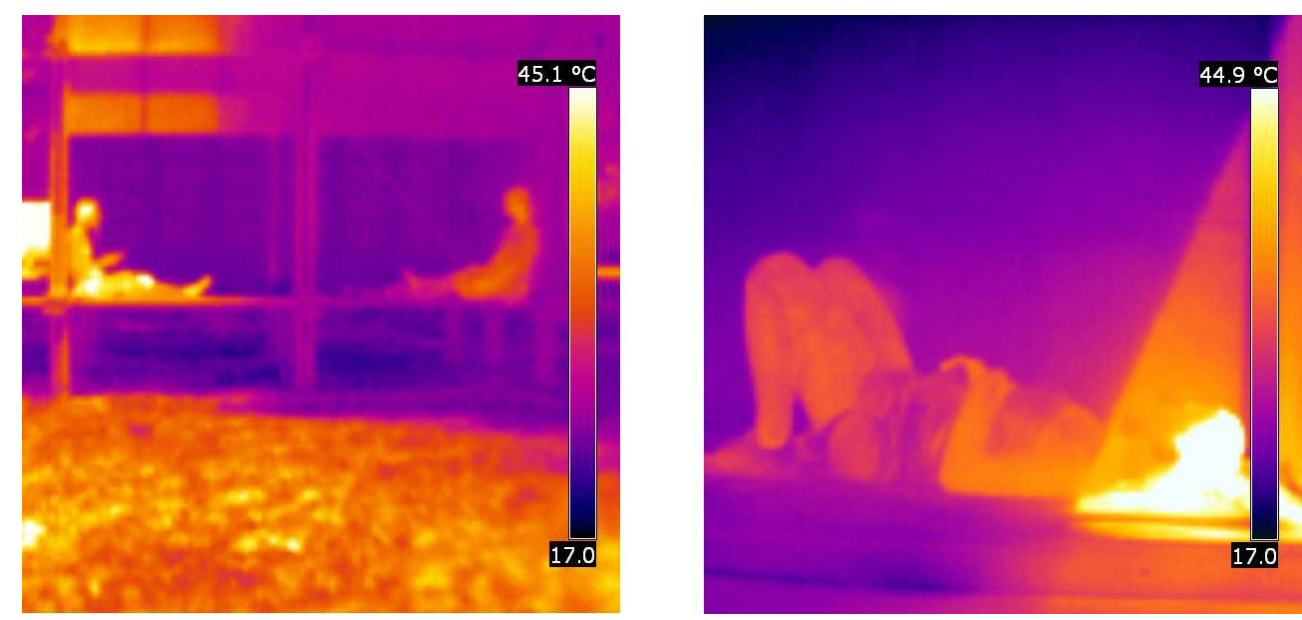

THE WARMER BODY SITTINg UNDER THE SUN, IN FRONT OF THE COOLER BODY IN THE SHADE (LEFT). AN INHABITANT RESTING IN THE SUN, WITH UNEVEN THERMAL PATTERNS ON HER BODY (RIgHT).

Source and copyright: Hélène Giguère-Duval, Groupe de recherche en Ambiances physiques, Université Laval, Canada

\section{Re-creating iconic physical ambiences}

17 The laboratory enables the interpretation of the main features of an existing space that contributes to the knowledge associated with similar typologies. The orthogonal structure of the laboratory provides an extensive array of transformability to re-create iconic physical ambiences that may connect us with historical precedents in architecture. In that context, Rietveld's liberated vertical and horizontal plane interactions, characteristic of the structure developed for the Schröder House (1924) was experienced during several transformations of the laboratory space. Historical buildings chosen for their distinct lighting ambiences inspired a series of planned experiments that were undertaken with graduate students (Giguère-Duval, 2012). Tadao Ando's recreation of the living room of the $4 \times 4$ House (2003) welcomed a generous sun ray that considerably enlarged the perception of the interior space with its entire wall aperture (figure 11). Alvar Aalto's Säynätsalo Town Hall (1951) generated an introverted space whereas the 
structure of the ceiling was particularly solicited to produce a rhythmic down lighting pattern issued mainly from a linear horizontal aperture located at the top of the laboratory space. The distribution of orthogonal shapes, mostly positioned on a single façade of the laboratory, created a lighting pattern that was somehow characteristic of Le Corbusier's chapel of Notre Dame du Haut in Ronchamp (1954). Inside the laboratory, panel interplays then produced a series of light sources organized at different heights along one of the interior walls, personalising the light and view relationships existing between windows and users.

18 The typology of Kahn's entry hall at Yale Center for British Art (1974), located in New Haven ( $\left.41^{\circ} 18^{\prime} \mathrm{N}\right)$, re-created in Quebec City $\left(46^{\circ} 49^{\prime} \mathrm{N}\right)$, illustrates an application of the laboratory in experimenting ambiences of historical precedents in architecture. Kahn's interest in environmental apprehension of architecture has been recognised especially in terms of the visual environment, but his work encompasses all systems responding to spatial logics, including the thermal and the acoustical dimensions. Kahn's use of the structural system as an integrator of ambient elements, and more predominantly daylighting, is clearly illustrated in his built work through great clarity and simple geometrical compositions that allow the demonstration of the complex expression of nature within space. The Yale Centre for British Art presents such conditions of environmental diversity, particularly on the visual aspect, within a basic grid structure. The main feature of the space consists of a top lighting typology that generates bright space (figures 12 (left) and 13 (left)) where light is reflected on the vertical surfaces. The adaptability of the laboratory enabled the transformation of the space approaching the effect of the top lit skylight of Kahn's museum typology (figures 12 (right) and 13 (right)). The original Kahn building, which is higher and located in an urban context, does not allow the view of tree branches towards the sky. In the laboratory, not only the trees are seen, moving, but we could also hear the wind and birds singing. The smaller version interpreted through the laboratory therefore offers a new version of a skylight typology, but still refers to the original version in terms of lighting sensation and thermal potential. It provided a different perspective of the space allowing for instance views of the trees that were present on our site located in Quebec City, but with similar sunlighting strategies. It thus provoked discussions on the possibilities to compare the space under a different latitude and physical context, but also to experience variations on the theme. Unlike Kahn's museum, there is no glass topping the laboratory roof aperture to prevent the windy breeze to come in and protect us from the rain. Figure 14 (left) presents the architectural drawing sections for the configuration of the Yale Center for British Art building typology, including the main body positions that occurred on site during the experiences. It also shows how the structure provided unexpected but rich possibilities of sitting positions and locations that were part of the Kahn's typological translation (figure 14 center). The recreated space somehow transcends its own inspiration and suggests the researcher to explore a semi-enclosed space that would welcome the heat of the sun, and the gentle breeze of the wind. It momentarily became a genius locus, an ideal and cozy place to spend a lunch break. 
Illustration 12: Louis I Kahn's Yale Center for British Art
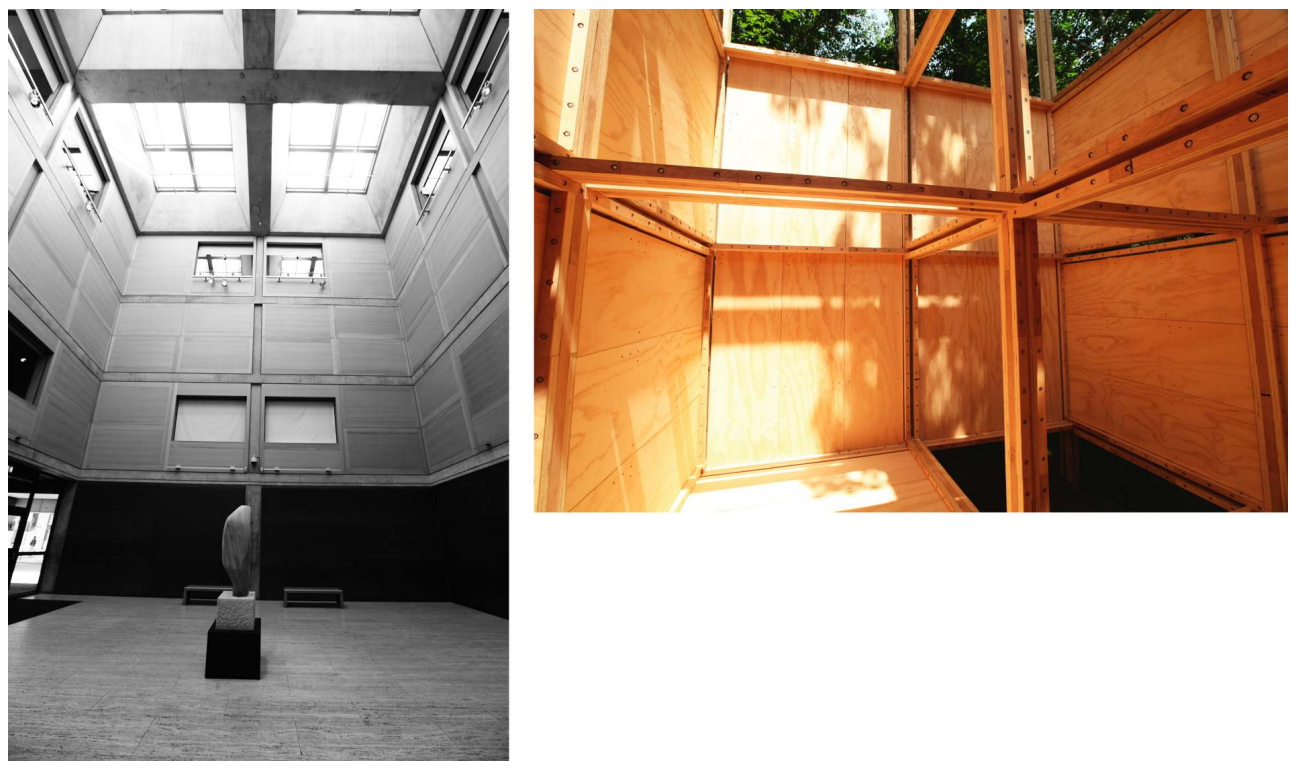

LOUIS I KAHN'S YALE CENTER FOR BRITISH ART IN NEW HAVEN, CT. $41,2^{\circ} \mathrm{N}$ LATITUDE (LEFT). THE TYPOLOgY OF KAHN'S ICONIC SKYLIGHT SYSTEM IS REINTERPRETED WITHIN THE PHYSICAL AMBIENCES LABORATORY ON A QUEBEC CITY WOODEN SITE, ON 21 JUNE AT NOON, 46, $8^{\circ} \mathrm{N}$ (RIgHT).

Source and copyright: Claude Demers, Groupe de recherche en Ambiances physiques, Université Laval, Canada

Illustration 13: Louis I Kahn's Yale Center for British Art
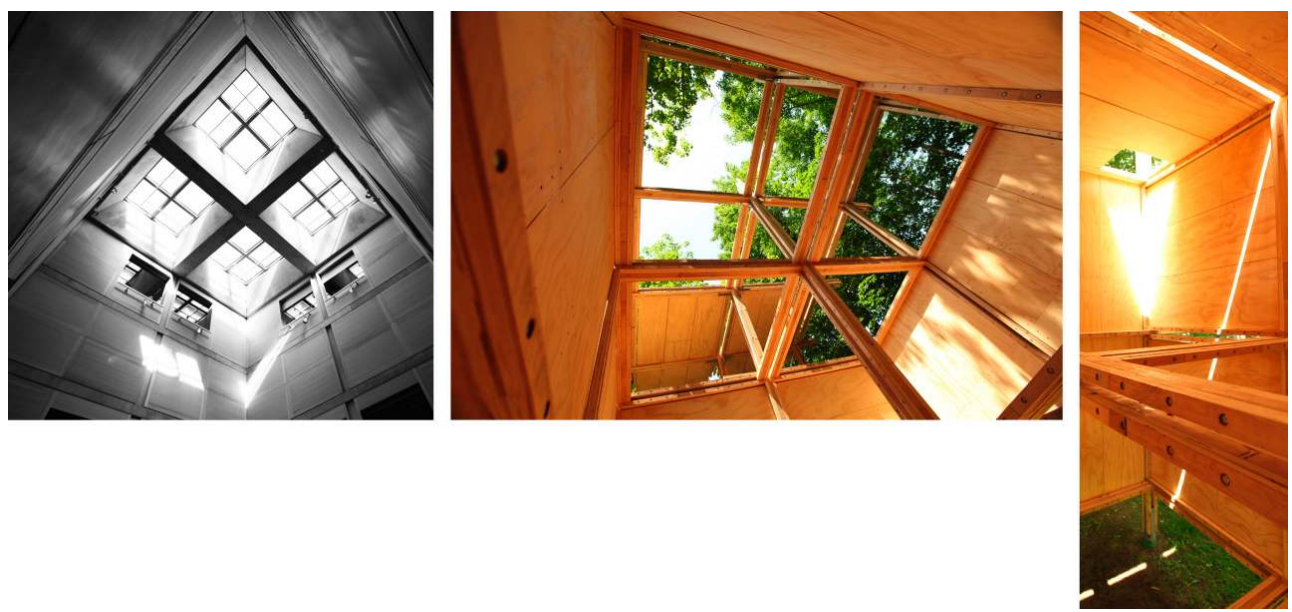

SKYLIGHT TYPOLOgY OF THE ENTRY HALL (LEFT). THE TYPOLOGY IS INTERPRETED WITHIN THE LABORATORY (CENTRE). A SIMILAR LIGHTINg PATTERN THAN IN THE ORIGINAL BUILDING IS CREATED IN ANOTHER TYPOLOgY INVOLVINg A SMALLER APERTURE (RIgHT).

Source and copyright: Claude Demers, Groupe de recherche en Ambiances physiques, Université Laval, Canada 

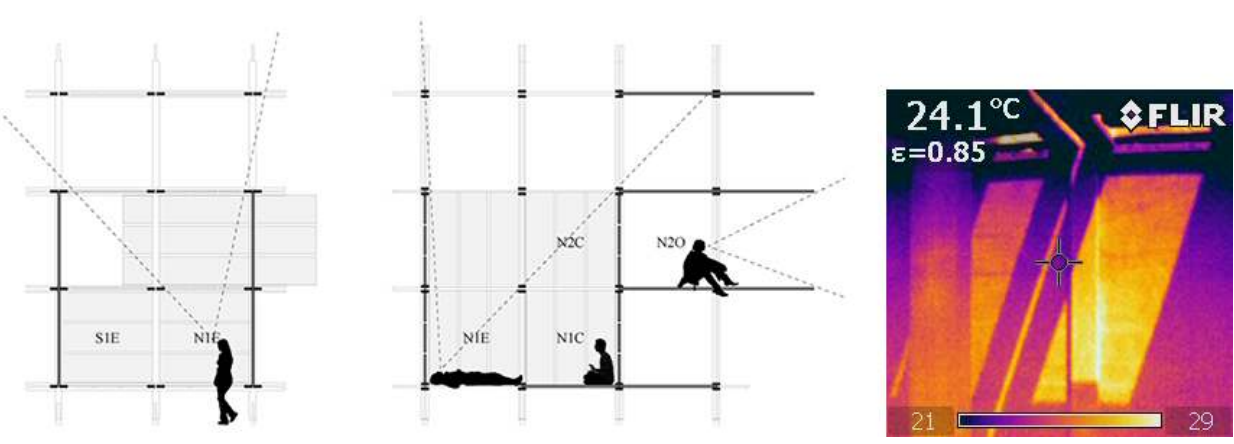

SECTION DRAWINGS SHOWING THE EXPERIMENTAL SET-UP IN RELATION TO THE SCALE OF THE STRUCTURE AND BODY POSITIONS (LEFT). THERMOgRAPHIC REPRESENTATION SHOWING THE THERMAL PATTERN ON VERTICAL SURFACES (RIgHT).

Source and copyright: Hélène Giguère-Duval, Groupe de recherche en Ambiances physiques, Université Laval, Canada.

The experience confirmed the interest to explore a Kahn's building typology in another context, which was surrounded by trees and offered views to nearby trees. It could be argued that a similar urban context to the existent site could be used, which would also be ideally located under the same latitude to best replicate the building's environmental challenges. In fact, the aim of the experiences was not to replicate the building's typology in its original or similar context, but to be able to associate some of its most promising features to another location and context.

\section{Representing the complexity of physical ambiences}

The interpretation of the qualitative and quantitative aspects recorded during an experience or survey must be translated into a meaningful format for the architect. The luminous and thermal journal of physical ambiances, a notion introduced in the Adaptive Architecture project (reference), consists of a communication medium that is both visual and written, on a common support. It proposes to organize in a single representation the qualitative and quantitative aspects of physical ambiances found in architecture. A journal may suggest a certain form of self-centeredness, consisting of organized information that originates from the point of view of the person that records it. The proposed mode of spatio-temporal representation introduced in the present research does not necessarily reflect everybody's response to a certain situation, nor does it generalize a perception. It rather informs on the necessity to represent one's perception of a space (Demers et. al., 2009). The familiar version of a journal consists in the written narrative of thoughts related to observations that emerge from an experience, a vision that is initially personal, but which could also reflect the inner thoughts of a larger group of people. It can also be viewed as a logbook of data recorded for later references to past experiences. Visual representations are more closely part the architect's realm to express ideas in a large spectrum of abstraction levels ranging from sketches, scale drawings, to photography. In our case, the particularity of the journal of physical ambiances is to represent an array of qualitative and quantitative reactions of the structure in relation to a specific space time and day. Interactive plans and sections demonstrate the systemic dynamic spatio-temporal properties of daylighting in parallel with the thermal, 
acoustical and olfactory environments (Bontemps, 2007). The representation proposes the insertion of a time line in relation to ambient results to build an architectural storyboard becoming a narrative of the existent ambiences. Figures 15 and 16 illustrate a representation of physical ambiences through such a storyboard format, enabling the illustration of a complex array of observations, including qualitative and quantitative aspects of architectural daylighting in relation to time (horizontal axis). The upper left black and white photograph constitutes the inspiration for the exploration, usually consisting of an interior viewpoint of an iconic existing building. Other colour photographs, located on the top row of the storyboard, relate to the more poetic conclusion of the experience of translating and adapting the "inspiration" into a spatial typology. Architectural drawings provide an overview of the final configuration: they include a perspective, a roof top plan with cast shadows, as well as the four elevations of the laboratory. Section drawings of the model were also drawn to offer a more detailed information relating body and structural adaptations (figure 14, left). The lower right half of the storyboard constitutes the survey of the ambiance where quantitative data obtained from the measuring equipment were introduced into a graph. It included daylighting levels, actual mean temperature, humidity of the air, and at times, noise level. Below the graph are located the physical ambience roses, which record the perception of inhabitants in terms of olfactory, thermal, visual and acoustical ambiences (Demers et. al. 2009). The photographs that are located near the graph acknowledge the temporal perceptions that were available during the surveys, and thus, the accumulated data in relation to the appropriate qualitative (physical ambiance rose) and the quantitative measurements. The storyboard also includes the previously discussed images taken automatically by the fixed camera in relation to time, such as illustrated in figure 8. These are located on the lower row, and constitute a reference showing the external appearance of the structure through time. The thermographic images and high dynamic range Photosphere representations also complement the observations recorded by inhabitants. Survey results of ambiences presented as a storyboard have the advantage to become powerful design and presentation tools for architects since it includes the spatiotemporal nature of an experience. The physical ambiences storyboard also raises questions of representation of daylighting atmospheres as it becomes possible to use the format to provide an architectural critique of the qualitative and quantitative results, using representational tools familiar to architectural practice. The storyboard engages a discourse about daylighting ambiences and relation to other ambiences (thermal, acoustical and olfactory), since the information is reinforced with the additional advantages of analyzing the space in its multisensory way. It moreover generates a dynamic way of looking at architectural ambiences. 


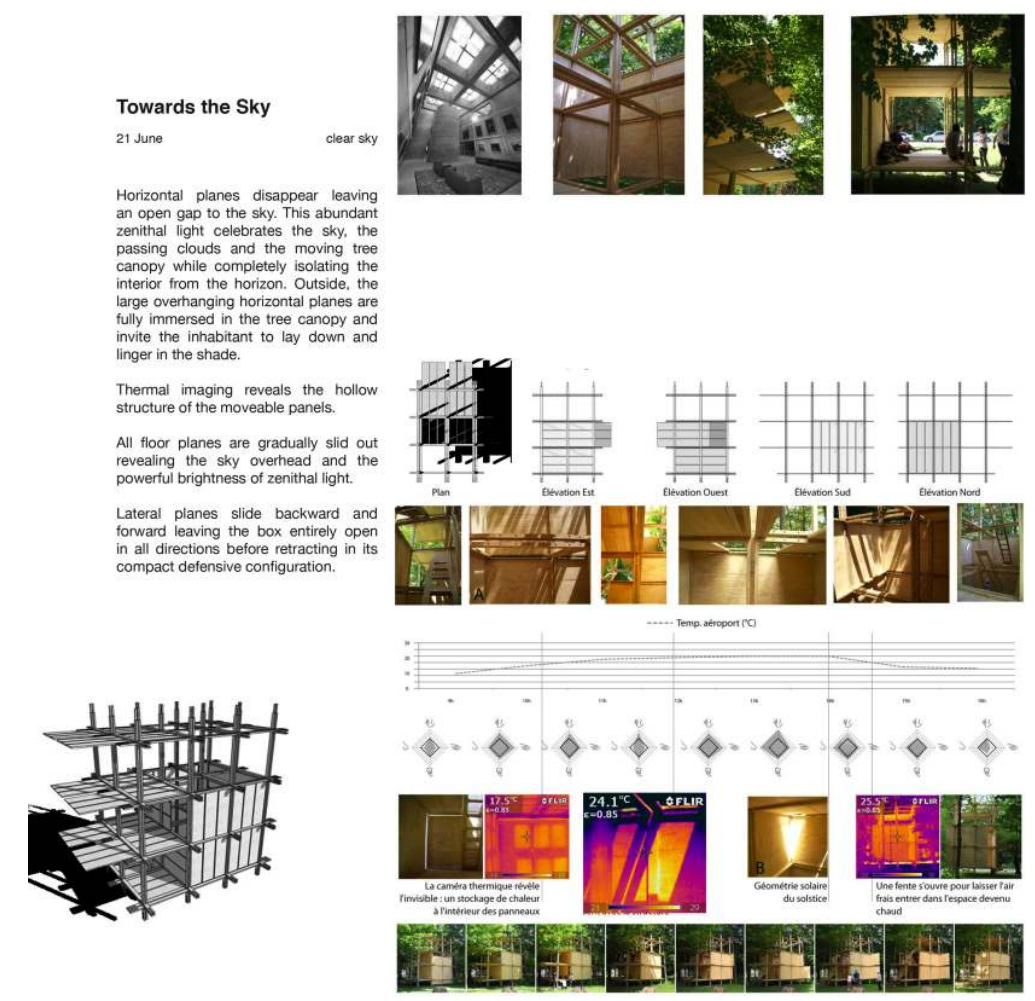

Source and copyright: Adapted from H Giguère-Duval et. al., 2012. Image Credit: Hélène Giguère-Duval, Groupe de recherche en Ambiances physiques, Université Laval, Canada.

21 Figure 16 shows another example of the storyboard representation of physical ambiences that were documented. This experience consists of large openings inspired from Ando's approach to views and light, framing views towards the exterior. This experience was especially interesting in terms of thermal delight, since the warm July day created opportunities for inhabitants to explore a wide spectrum of body positions in relation to the comfortable sunlighting pattern (figure 16; enlarged thermal images shown in figure $11)$. 

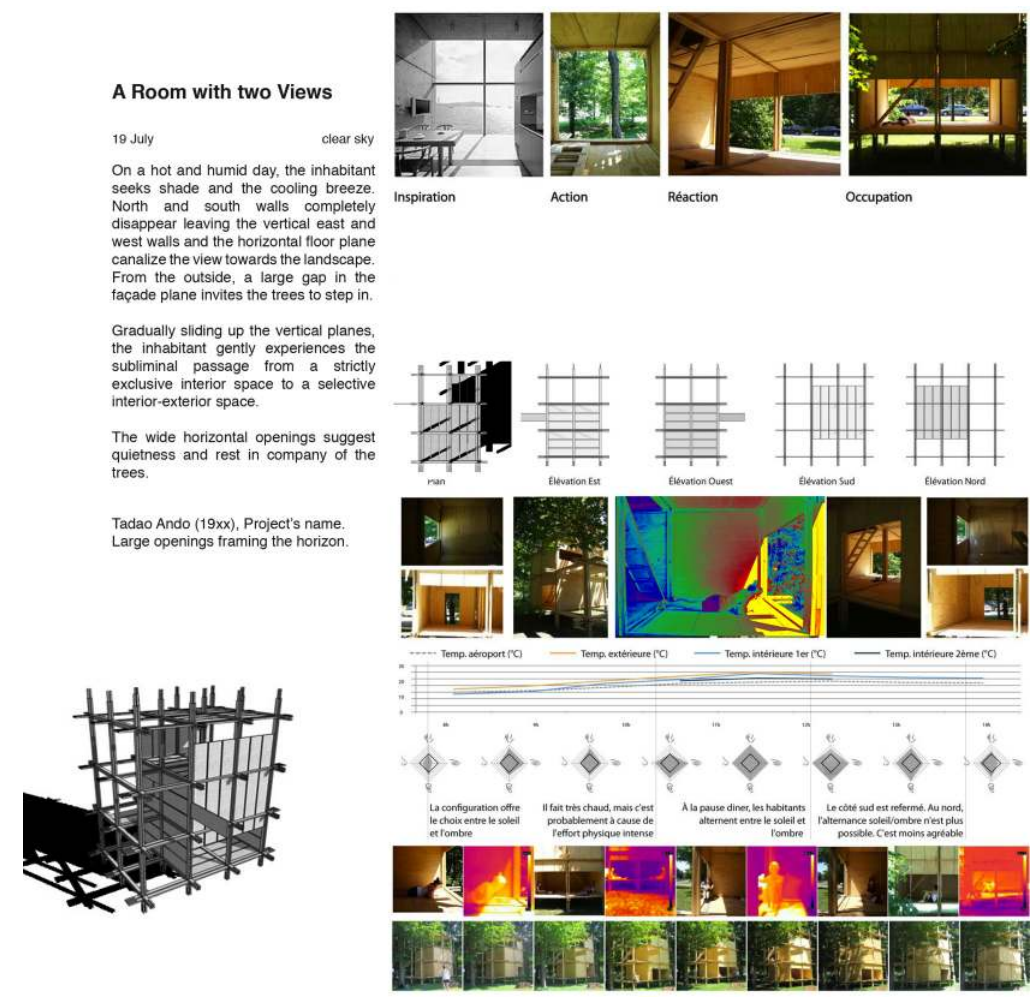

Source and copyright: Adapted from H Giguère-Duval et. al., 2012. Image Credit: Hélène Giguère-Duval, Groupe de recherche en Ambiances physiques, Université Laval, Canada.

\section{Speculating on future ambiences}

Illustration 17: From physical modeling (left) to full-scale (right)
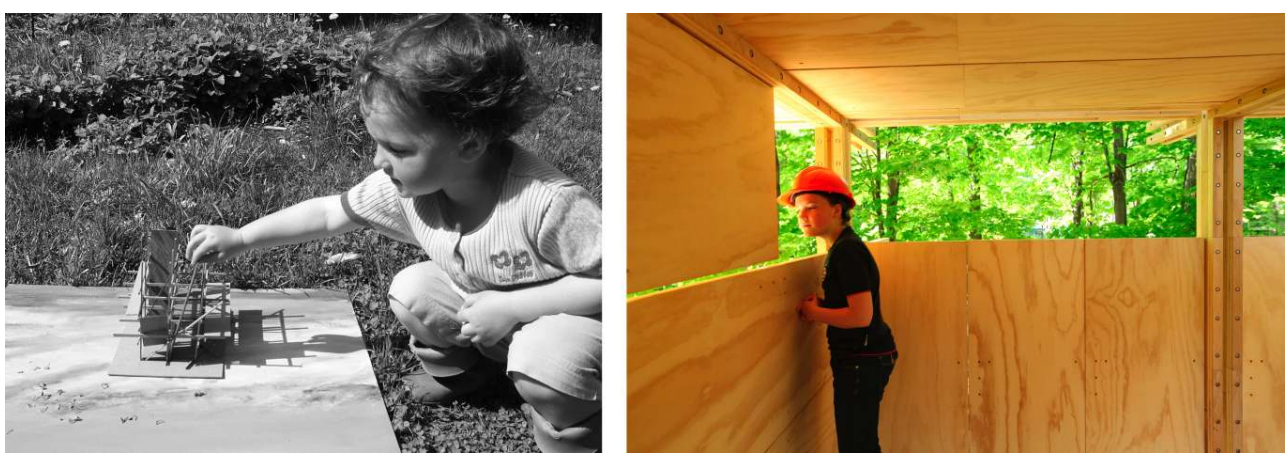

EXPERIENCING ARCHITECTURAL TYPOLOgIES THROUgH SPACE AND TIME: AN INHABITANT IS ENgAgINg IN AN ACT OF REVERIE, A UNIQUE OPPORTUNITY TO ENgAgE IN A TACTILE, MORE SENSORIAL ASSESSMENT OF FUTURE AMBIENCES.

Source and copyright: Claude Demers, Québec, Canada

The laboratory represents a unique tool to explore the entire potential of physical ambiences in relation to spatial diversity. In many ways, in situ experimentations share some interesting similarities with the manipulation of the conceptual scale model. The mobility of the vertical and horizontal elements in the scale model fostered speculative 
thought suggesting new building typologies and facade experimentations of the structure (fig. 3). The experience of interacting with the physical scale model propelled us into a relatively abstract world of mobility where architecture was no longer inert but could actually do things (figure 17). It allowed a live action-reaction response of the adaptable structure in relation to users and the environment. The in situ experimentations relate to the complex nature of the physical context of the site, which includes not only the visual aspects, but also the tactile, more sensorial components. Although manipulations of the real scale laboratory provided less immediate and dramatic changes than the scale model due to obvious technical reasons, they more physically and emotionally responded to the need to understand the complex nature of adaptive opportunities. Adaptive experimentations at the scale of space have expanded the notion of architecture and interiority towards a greater relation with the exterior environment. The physical ambiences laboratory had the advantage to explore at a fundamental level the quantitative and qualitative potential of a wood structure to fully transform itself into several spatial configurations according to desires of its inhabitants (figure 18). It created moments of delight and "reverie" before, during and after the process of transformation of the space.

These experiments have demonstrated that students taking part in design studio classes represent the perfect corpus of inhabitants to recreate, explore and analyse a series of historical examples of architectural typologies. The pedagogical potential of the use of the laboratory in schools of architecture should thus be developed as an opportunity to expand the exploration of historical past ambiences beyond traditional means of analysis. The study of historical precedents could thus involve students in a critical process of thinking and action taking place in a 1:1 spatial typology. The laboratory would, moreover, provide design teaching with an innovative tool for students to inhabit, measure, draw and write about their sensorial, ergonomic and other physical aspects of their connection with an ambience. The pedagogical innovation of the physical ambience laboratory lies in the spontaneous transformation of typologies by students, which should create a new intersection between the theoretical teaching of past typologies and the design of new spaces, favouring the integration of the complex nature of ambiences early in the design process. These explorations should advantageously inform the design activity and complement simulations and scale models. 


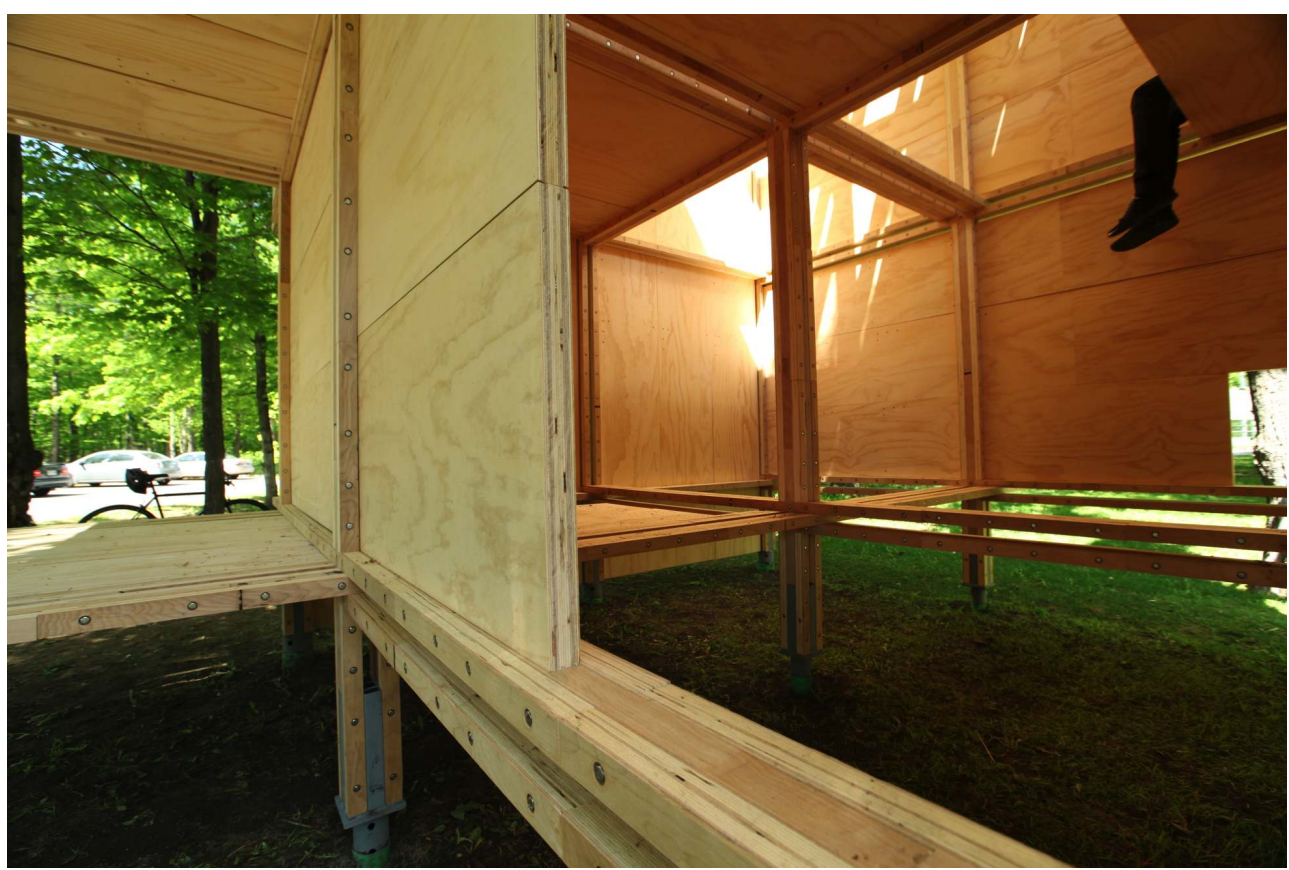

Source and copyright: Claude Demers, Groupe de recherche en Ambiances physiques, Université Laval, Canada

Connected with the idea of the typological approach, valued in the design process, the experience of historic built forms constitutes a necessary beginning and should not remain a mere objective or result since architecture consists in exploring new design possibilities adapted to specific contexts. The real value of the laboratory probably resides in its capacity to generate unusual, ambiguous spaces that often appear accidentally while tempting to re-create and interpret a historical precedent of architecture. The mobility of the vertical and horizontal planar elements of the components of the structural system could for instance foster speculative thoughts, suggesting new building typologies and facade experimentations. Spaces created during the transformation process of sliding walls and floors therefore offer even more challenging spaces than the consciously sought after configuration.

There are obvious limits to such an adaptable and transformable system, which may appear to greatly abstract the realities faced with actual past or existing space such as the imposed orthogonal grid, the variety of materials and colors used in the panel system, as well as the human interactions implied to move the panels within the system. However, these limits also create opportunities to reinterpret historical precedents and typologies, translating the essential components that connect them between interior and exterior, a variable that greatly relates to opacity and transparency. Further developments of the laboratory should address those limits, especially since the reinstallation of the structure on other sites is possible.

The physical ambiences laboratory raises new issues related to the interpretation, prediction, and representation of physical ambiences at all stages of a project from its inception, design, construction and post-occupancy evaluations. A physical ambience can only exist by the systemic resolution of matter, energy and occupancy (Adolfe, 1998). It emerges from the sensible knowledge of the architect, upstream of the project and its 
capacity to deliver ideas within a coherent system that responds to the user's needs while minimizing its ecological footprint. At this critical moment in architectural education and practice where technical considerations related to sustainable design seem to dominate the agenda, we should be reminded of the possibility for a more dynamic integration of matter, energy and the occupants at all scales and stages of the design process. This research suggests that adaptive opportunities and reinterpretation of existing ambiences could ultimately translate into new spaces to experience environmental delight for responsive inhabitants.

\section{BIBLIOGRAPHY}

Adolfe, Luc. 1998. La recherche sur les ambiances architecturales. In: Adolfe, Luc. (ed). 1998.

Ambiances architecturales et urbaines. Les cahiers de la recherche architecturale. $n^{\circ} 42-43$. Marseille: Éditions Parenthèses. p. 7-12.

Arnheim, Rudolf. 1978. [1977]. The Dynamics of Architectural Form. Oakland, California: University of California Press.

Baker, Nick \& Standeven, Mark. 1995. A behavioural approach to thermal comfort assessment in natural ventilated buildings. In: Proceedings of CIBSE National Conference 1995. Chartered Institution of Building Services Engineers. 1-3 October. Eastbourne, UK.

Bontemps, Arnaud; Potvin, André \& Demers, Claude. 2007. The dynamics of Physical Ambiences. In: Liley, Brian \& Beesley, Philip (eds). Expanding bodies: art, cities, environment. Proceedings of Acadia. 1-7 October 2007. Halifax: Riverside Architectural Press and PUNS Press. p. 174-181.

Colquhoun, Alan. 1981. The type and its transformation (chapter 2). In: Essays in architectural criticism: modern architecture and historical change. Cambridge, Massachusetts and London England: The MIT Press. p. 42-75.

Demers, Claude; Potvin, André \& Giguère-Duval, Hélène. 2013. Inhabiting Adaptive Architecture: Environmental Delight in Adaptable Spaces. In: Proceedings of the International Conference on Adaptation and Movement in Architecture (ICAMA), 11-12 October. Toronto: Ryerson University.

Demers, Claude. 1997. The Sanctuary of Art: Images in the design and assessment of light in architecture. Ph.D. Thesis. Cambridge: University of Cambridge. Available at: https:// www.repository.cam.ac.uk/handle/1810/252316 (Accessed 3 June 2016).

Demers, Claude, Potvin André \& Dubois, Marie-Claude. 2009. Environmental Satisfaction and Adaptability: The Physical Ambience Rose as a global comfort representation. In: Demers, Claude \& Potvin, André (eds). 2009. Architecture Energy and the Occupant's Perspective. Proceedings of the $26^{\text {th }}$ International Conference on Passive and Low Energy Architecture (PLEA), 22-24 June. Québec: Les Presses de l'Université Laval (PUL). p. 2, 3 et 6.

Giguère-Duval, Hélène ; Demers, Claude \& Potvin, André. 2012. Journal lumineux et thermique d'un espace adaptable: prediction et analyse des ambiances. In: Thibaud, Jean-Paul \& Siret, Daniel (eds.). 2012. Ambiances in action - Ambiances en actes : Proceedings of the 2nd international congress on ambiances - Actes du 2nd congrès international sur les ambiances, Montréal, 19 - 22 septembre 2012. 
Grenoble : Réseau international Ambiances : École nationale supérieure d'architecture de Grenoble. p. 209-214.

Hawkes, Dean. 1996. Types, norms and habits in environmental design. In: The environmental tradition. 1st ed. London: E \& FN Spon.

Huet, Bernard. 1993. Typological theories in architectural design. In: Farmer, Ben \& Louw Hentie (eds). Companion to contemporary architectural thought. London \& New York: Routledge. p. 393-395.

Kahn, Louis I. 1959. In: Twombly, Robert. 2003. Louis I Kahn: Essential texts. New York: W.W. Norton \& Company.

Kiesler, Frederick J. 1949. Manifeste du Corréalisme. Originally in L'Architecture d'Aujourd'hui. 2, 2.6. 1949, p. 80-105. Facsimile In: Dieter Bogner. 1997. Friedrich Kiesler, Inside the Endless House. Wien : Böhlau.

Knowles, Ralph L. 1999. Rituals of Place. University of Southern California. Available at: http:// www-bcf.usc.edu/ rknowles/rituals_place/rituals_place.html (Accessed 3 June 2016).

Lam, William M. C. 1986. Sunlighting as Formgiver for architecture. New York: Van Nostrand Reinhold Co.

Le Corbusier. 1923. Towards a new architecture. Translated by Frederick Etchells, London, Butterworh Architecture, reprinted in 1989.

Lépine, Pierre. 2011. La diversité environnementale en architecture : Potentiel de l'image numérique pour l'exploration des ambiances lumineuses et thermique in situ. Mémoire de maitrise scientifique en architecture (M.Sc.). Université Laval, Québec.

Norberg-Schulz, Christian. 1980. Genius Loci: Towards a Phenomenology of Architecture. New York: Rizzoli.

Potvin, André, Demers, Claude \& DuMontier, Cédric. 2014. A Design Built Approach in the Development of a Wooden Adaptive Architectural System. In: Salenikovich, Alexander (ed). 2014. World Conference on Timber Engineering (WCTE), Québec, 10-14 août 2014. p. 6-10.

Woloszyn, Philippe \& Siret, Daniel. 1998. Du complexe au simplex. In: Adolfe, Luc. (ed). 1998. Ambiances architecturales et urbaines. Les cahiers de la recherche architecturale. ${ }^{\circ} 42-43$. Marseille: Éditions Parenthèses. p. 49-61.

Zevi, Bruno. 1991. Light as architectural form. World Architecture. $\mathrm{n}^{\circ} 14$, p. 56-59.

\section{ABSTRACTS}

The built environment offers an impressive corpus of spatial typologies on which architects and users may build their knowledge based of ambiences. This corpus primarily consists of existing buildings originating from a wide spectre of historical backgrounds, but it could also include past ambiences. A physical ambiences laboratory has recently been developed, built, and inhabited to compare existing and past ambiences, but foremostly speculate on future ambiences. It consists of a full-scale, adaptable structure that allows for the experience of architectural typologies, and enables spatial transformations through time. Building the adaptable structure in an outdoors environment aims to connect the theory of ambiences with the actual complexity of experiencing on a site, which cannot be adequately approached with digital simulation. The definition of an ambience therefore involves complexity because of the changing nature of the environmental conditions that generates it, such as light, wind, sun, and sound, creating varying distribution patterns of natural fluxes. This research-creation project recognizes that the people- 
environment issue constitutes an essential basis to the creation of genuine genius loci. The research suggests that adaptive opportunities and reinterpretation of existing ambiences could ultimately translate into new spaces to experience environmental delight for responsive inhabitants.

L'environnement bâti offre un corpus de typologies spatiales sur lesquelles il est possible de valider les notions d'ambiances architecturales. Ce corpus se compose de bâtiments existants provenant de contextes historiques diversifiés, mais pourrait inclure des ambiances issues du passé. Un laboratoire d'ambiances physiques a été créé, construit et habité afin de comparer les ambiances actuelles et passées, mais aussi pour spéculer sur les ambiances futures. Il se compose d'une structure adaptable, permettant l'expérience des typologies architecturales ainsi que des transformations spatiales à travers le temps. L'exploitation de l'environnement extérieur vise à relier la théorie des ambiances à la complexité de l'expérience d'un site, aspect qui ne saurait être abordé de manière adéquate avec la simulation numérique. La définition d'une ambiance implique donc la complexité en raison de la nature changeante des conditions environnementales qui le génèrent, comme la lumière, le vent, le soleil, et le son, en créant différents modèles de distribution des flux environnementaux. Ce projet de recherche-création reconnait la relation personnes-environnement comme base essentielle à la création d'un véritable genius loci. La recherche suggère que les possibilités adaptatives et la réinterprétation d'ambiances existantes pourraient se traduire par la création de nouveaux espaces pour favoriser une expérience environnementale optimisée.

\section{INDEX}

Keywords: adaptable, ambience, architecture, experience, inhabitant, light, representation, structure, typology, visualization

Mots-clés: adaptable, ambiance, architecture, experience, habitant, lumière, représentation, structure, typologie, visualisation

\section{AUTHORS}

\section{CLAUDE MH DEMERS}

Claude Demers is a Professor of architecture at Laval University and a graduate from the University of Cambridge, innovating on the integration of qualitative and quantitative assessments of daylighting in architecture. Co-founder of the Groupe de Recherche en Ambiances Physiques, she is involved in biophilic architecture and occupant's satisfaction, associating the importance of design to user's behaviour. She is producing fundamental and applied research, favouring the integration of bioclimatic design strategies at the scales of urban, architectural and detail.

Contact : claude.demers@arc.ulaval.ca

\section{ANDRÉ POTVIN}

André Potvin graduated from the University of Cambridge. He is a Professor, actively involved in research and teaching environmental design at graduate and postgraduate levels. Dr Potvin cofounded the Groupe de recherche en ambiances physiques (GRAP) dedicated in passive environmental control strategies at the urban, architectural and detail scales and the director of the Institut environnement, développement et société (EDS), Laval University. His most recent 
research and consultant works include bioclimatic architecture, urban microclimatology and environmental adaptability.

Contact : andre.potvin@arc.ulaval.ca 